\title{
Non-dieting group interventions for overweight and obese women: what predicts non-completion and does completion improve outcomes?
}

\author{
Alison J Bradshaw ${ }^{1}$, Caroline C Horwath ${ }^{1, *}$, Lisa Katzer ${ }^{1}$ and Andrew Gray ${ }^{2}$ \\ 'Department of Human Nutrition, University of Otago, PO Box 56, Dunedin, New Zealand: ${ }^{2}$ Department of \\ Preventive and Social Medicine, University of Otago, Dunedin, New Zealand
}

Submitted 23 February 2009: Accepted 11 November 2009: First published online 22 December 2009

\begin{abstract}
Objective: To determine factors which predict non-completion of group nondieting interventions for overweight women, and to investigate whether completion improves outcomes.

Design: First, baseline predictors of non-completion were identified; then changes at 10 weeks and 12 months were compared between completers and non-completers of 10-week non-dieting interventions.

Setting: General community.

Subjects: Participants were 119 women (aged $25-65$ years, BMI $\geq 28 \mathrm{~kg} / \mathrm{m}^{2}$ ) with at least one cardiovascular risk factor. Participants who attended at least eight of the ten sessions were classified as completers, and non-completers were those who attended fewer than eight sessions. Measures included BMI, blood pressure, psychological distress, lifestyle behaviours and eating self-efficacy.

Results: Logistic regression analyses indicated that women were less likely to be noncompleters at non-dieting group programmes if, at baseline, they were more highly educated or had healthier nutrition behaviours (controlling for education). Only healthier nutrition behaviour was negatively associated with non-completion in the final model. Twelve months after the intervention, completers showed significantly greater improvements in body weight (mean change $-0.53 \mathrm{~kg}$ ), systolic and diastolic blood pressure $(-6 \cdot 3$ and $-4 \cdot 1 \mathrm{mmHg}$, respectively), stress management behaviour score $(+0 \cdot 5)$ and psychotic symptoms score $(-0 \cdot 1)$ than non-completers (all $P<0 \cdot 05$ ). Conclusions: Highly educated women already engaging in some healthier lifestyle choices were less likely to be non-completers in non-dieting group programmes. Since important treatment outcomes vary according to attendance, future trials of non-dieting interventions should report the effects of completion on outcomes.
\end{abstract}

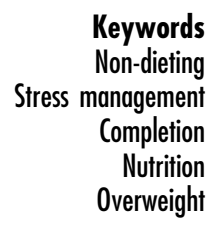

In response to the poor long-term success and high rates of weight regain associated with deliberate caloric restriction $^{(1,2)}$, non-dieting approaches (also known as 'health at every size') have been advocated for overweight and obesity ${ }^{(3,4)}$. Non-dieting approaches encourage eating in response to physiological hunger and satiety cues, rather than deliberate restriction of food intake $^{(5-7)}$. This style of eating, termed intuitive eating ${ }^{(6,8)}$, is proposed to lead to a reduction in eating that occurs when one is not physically hungry. Such approaches do not involve a preoccupation with food regimens or weight-loss goals; reduce the feelings of guilt and deprivation often associated with dieting ${ }^{(6)}$; and help to alleviate the psychological distress caused by long-term dieting failure and perceived lack of self-control ${ }^{(9)}$.

In contrast to the large body of literature evaluating interventions that have a weight loss or dieting focus, there have been relatively few published randomized trials of non-dieting interventions ${ }^{(5,7,10-21)}$. Non-dieting group-based programmes for overweight and obese women have produced greater psychological benefits $^{(5,7,12,15)}$ and improvements in eating behaviours ${ }^{(5,7,15)}$ than dieting (i.e. weight loss-focused) group programmes. Most non-dieting programmes are associated with weight maintenance ${ }^{(5,7,11,15,16,19,20)}$. Inclusion of intensive stress management training in a non-dieting group programme for overweight women has been shown to enhance stress management and medical symptom outcomes, but not weight outcomes ${ }^{(20)}$.

To date, among studies of group non-dieting interventions $^{(5,7,10,16-19,21)}$, only one has reported attendance/ completion data ${ }^{(12)}$. Rapoport et al. $^{(12)}$ reported significantly higher binge eating, but no significant BMI, depression or demographic differences in women who 
attended fewer than seven out of ten sessions compared with those who attended at least seven sessions. In an evaluation of a group intervention focused on training in techniques for eliciting the relaxation response, participants who attended at least seven of ten sessions had lower levels of psychological distress, were more highly educated and more likely to be married and gainfully employed at baseline than those who attended fewer than seven sessions ${ }^{(22)}$. Even in group interventions with a clear weight-loss focus, predictors of completion are seldom reported ${ }^{(23)}$.

The aims of the current study were: (i) to examine whether demographics, lifestyle behaviours, health outcomes or psychological factors predict non-completion of group non-dieting interventions for overweight and obese women; and (ii) to test the hypothesis that completers benefit more from group non-dieting interventions than non-completers. To our knowledge, this is the first study to examine these questions. The challenging process of shifting from diet-thinking and weight-loss goals to intuitive eating ${ }^{(6,20)}$ may be facilitated by more regular attendance at group programmes, and thus we hypothesized that completers experience greater benefits than non-completers.

\section{Methods}

The current study is part of a larger randomized trial of a non-dieting stress reduction intervention ${ }^{(20)}$. The trial, comparing three non-dieting interventions, took place in Dunedin, New Zealand between 2002 and 2003. Two of these non-dieting interventions were group programmes: one focused on stress reduction and relaxation training; the other focused on healthy lifestyle change.

\section{Participants}

Women were recruited by newspaper advertisements and locally distributed fliers. Participants were aged between 25 and 65 years, with a $\mathrm{BMI} \geq 28 \mathrm{~kg} / \mathrm{m}^{2}$ (indicating substantial overweight or obesity) and at least one other CVD risk factor (hypertension $\geq 140 / 90 \mathrm{mmHg}$, total cholesterol $\geq 5.5 \mathrm{mmol} / 1$, type 2 diabetes or current smoker). Respondents were excluded if they had been previously diagnosed with heart disease or cancer, were pregnant, insulin-dependent, had binge-eating disorder, were taking medications for a psychiatric illness, or were involved in another lifestyle intervention programme.

In the larger trial, randomization was stratified by age and BMI and performed independently by a statistician. Study protocol was approved by the Ethics Committee of the University of Otago, Dunedin, New Zealand.

\section{Interventions}

During the first phase (10 weeks) of the group non-dieting interventions, participants attended weekly two-hour group sessions. During the second phase ( 8 months), group sessions were provided biweekly and then monthly, with the aim of reinforcing programme content through the provision of ongoing support for healthy behaviour change.

In both group interventions (Programme 1, P1 and Programme 2, P2), participants were encouraged to let go of their dieting habits, and shift focus away from body-weight goals towards developing healthy lifestyle changes that are sustainable in the long term. Although guidelines on healthy eating were provided, interventions recommended eating that was regulated by body signals of hunger and satiety, and encouraged greater awareness of the triggers to eating that are unrelated to physical hunger. The differences between $\mathrm{P} 1$ and $\mathrm{P} 2$ are described in detail elsewhere ${ }^{(20)}$. Briefly, P1 was based on the Harvard Mind/ Body Medical Institute Medical Symptom Reduction programme ${ }^{(24,25)}$. Each session included intensive instruction and practice in eliciting the relaxation response. Techniques included progressive muscle relaxation, abdominal breathing and hatha yoga. Based on Social Cognitive Theory ${ }^{(26)}$, P2 included a greater focus on nutrition and physical activity than P1, but was consistent with nondieting principles. P2 had no relaxation response training.

\section{Attendance criteria}

Participants who attended at least eight of the initial ten group sessions were classified as completers. Women who attended seven or fewer sessions were regarded as non-completers.

\section{Measures}

Participants completed assessments at baseline, 10 weeks and 12 months.

\section{Demographics}

At the baseline visit, information on demographic factors such as age, highest attained education level, relationship status and occupation was collected.

\section{Lifestyle behaviours}

The fifty-two-item Health-Promoting Lifestyle Profile II (HPLP-II) ${ }^{(27)}$ was used to assess the frequency with which participants engaged in a variety of lifestyle behaviours and has been used in evaluations of the Harvard Mind/ Body Medical Institute's Medical Symptom Reduction programme ${ }^{(22,25)}$. Results of three subscales from the HPLP-II (stress management, physical activity and healthy nutrition-related behaviours) are presented. At each visit, participants provided information on smoking status.

\section{Health outcomes}

For height and weight measurements, participants removed shoes and wore light clothing. Height was measured to the nearest $0 \cdot 1 \mathrm{~cm}$ using a stadiometer (Holtain Ltd, Crymych, UK) and weight was measured to the nearest $0 \cdot 1 \mathrm{~kg}$ using a calibrated electronic scale (model Alpha 770; Seca, Hamburg, Germany). BMI $\left(\mathrm{kg} / \mathrm{m}^{2}\right)$ was calculated to the 
nearest $0 \cdot 1$ units. Blood pressure was assessed using an Accoson sphygmomanometer (Hospital Model; London, UK), with participants in the seated position. Systolic and diastolic pressures were measured twice, and an average calculated. Large or small blood pressure cuffs were used as appropriate.

\section{Psychological factors}

The Eating Self-efficacy Scale ${ }^{(28)}$ measured perceived difficulty in controlling overeating in different situations.

The Revised Symptom Checklist-90 (SCL-90-R) ${ }^{(29)}$ has been used extensively to monitor psychological distress $^{(24,30)}$. The current study includes results for the ninetyitem Global Severity Index (GSI), and the nine dimensions of somatization, obsessive-compulsiveness, interpersonal sensitivity, depression, anxiety, hostility, phobic anxiety, paranoid ideation and psychoticism.

\section{Analyses}

To ensure that completer and non-completer groups were of sufficient size for multivariate analysis, a cut-off of at least eight sessions was used to denote completion. Means, standard deviations and frequencies (where appropriate) were calculated for all baseline variables.

Participants in the two different group interventions (P1 and P2) showed few statistically significant differences at baseline. The combination of participants from these two group non-dieting interventions was decided upon a priori, as there was no expectation that the predictors would differ in their effect between the two programmes, in order to maximise statistical power and to permit more complex multivariate models to be investigated. Interactions between programmes and predictors were checked in all cases.

Univariate logistic regression models were employed to determine which non-modifiable factors (age, education, relationship status and employment) significantly differ- entiated non-completers (coded as 1) from completers (coded as 0). A series of logistic regression models was then developed, including other potential discriminating measures, one at a time (baseline BMI, weight, blood pressure; baseline eating self-efficacy, HPLP-II and SCL90-R scores; and smoking status), with all of the nonmodifiable predictors which had univariate $P<0 \cdot 20$ included in each model. Smoking status was modelled using three categories: never smoker, former smoker and current smoker. Pairwise comparisons between levels of categorical variables (smoking and employment status) were examined for statistical significance only where the overall effect was statistically significant. Variables which had $P<0 \cdot 10$ in the two-variable logistic regression models were then included in the final multiple logistic regression model. Final results were considered significant where $P<0 \cdot 05$. Because there were only fifty cases of non-completers and sixty-nine completers, only five predictors could be included in the final model.

The $t$ test (assuming unequal variance) was employed to identify differences in 10-week and 12-month changes between completers and non-completers.

All analyses were conducted using the SAS statistical software package version $9 \cdot 1 \cdot 2$ (SAS Institute Inc., Cary, NC, USA) ${ }^{(31)}$.

\section{Results}

Of the 119 participants who completed baseline assessments, sixty-nine (58\%) attended eight or more sessions and fifty (42\%) attended fewer than eight sessions. Demographic characteristics for participants (including for completers and non-completers) are shown in Table 1. At baseline, the majority of participants were middle-aged, educated, in relationships, employed for wages or salary, obese, and with moderate blood pressure.

\begin{tabular}{|c|c|c|c|}
\hline Characteristic & Total & Completers & Non-completers \\
\hline$n$ & 119 & 69 & 50 \\
\hline Mean age (years) & $46 \cdot 3$ & $46 \cdot 6$ & $46 \cdot 0$ \\
\hline \multicolumn{4}{|l|}{ Education (\%) } \\
\hline Did not complete high school & $19 \cdot 3$ & $13 \cdot 0$ & $28 \cdot 0$ \\
\hline Completed at least high school & $80 \cdot 7$ & $87 \cdot 0$ & $72 \cdot 0$ \\
\hline \multicolumn{4}{|l|}{ Relationship status (\%) } \\
\hline With partner & $74 \cdot 8$ & $75 \cdot 4$ & $74 \cdot 0$ \\
\hline Without partner & $25 \cdot 2$ & $24 \cdot 6$ & $26 \cdot 0$ \\
\hline With children & $55 \cdot 5$ & $59 \cdot 4$ & $50 \cdot 0$ \\
\hline Without children & $44 \cdot 5$ & $40 \cdot 6$ & $50 \cdot 0$ \\
\hline \multicolumn{4}{|l|}{ Occupation (\%) } \\
\hline Employed full-time & $31 \cdot 9$ & $30 \cdot 4$ & $34 \cdot 0$ \\
\hline Employed part-time & $41 \cdot 2$ & $40 \cdot 6$ & $42 \cdot 0$ \\
\hline Not employed & $26 \cdot 9$ & $29 \cdot 0$ & $24 \cdot 0$ \\
\hline \multicolumn{4}{|l|}{ Smoking status (\%) } \\
\hline Never smoker & $57 \cdot 1$ & $56 \cdot 5$ & $58 \cdot 0$ \\
\hline Former smoker & $23 \cdot 5$ & $30 \cdot 4$ & $14 \cdot 0$ \\
\hline Current smoker & $19 \cdot 3$ & $13 \cdot 1$ & $28 \cdot 0$ \\
\hline
\end{tabular}




\section{Intervention-by-predictor interactions}

Of the intervention-by-predictor interactions, only the effect of anxiety was statistically significant $(P=0 \cdot 041$, all other $P>0 \cdot 165)$. The effect of anxiety was opposite to that expected (higher values were associated with completion in P2 and non-completion in P1) and the effect of anxiety was not statistically significant within either intervention group $(P=0.095$ for $\mathrm{P} 1, P=0.234$ for P2). As this result is difficult to interpret, the results in Table 2 for anxiety are from the main effects model which does not include the interaction, and which shows no overall evidence of an effect of anxiety $(P=0.955)$.

\section{Predictors of non-completion: logistic regression analyses}

Univariate analyses of non-modifiable variables (age, education, relationship status and occupation) showed that only education significantly differentiated completers from non-completers. The odds of those who did not complete high school being non-completers were 2.59 (95\% CI 1·02, 6.60; $P=0 \cdot 046$; see Table 2). Subsequently, all other baseline predictors were examined in separate logistic regression analyses, in which education was controlled for. Smoking status showed potential for differentiating completers from non-completers $(P=0.043$ for the overall test of differences between all three categories). However, pairwise comparisons between the smoking categories revealed no statistically significant differences between current and never smokers or between former and never smokers, although there was strong evidence of a difference between current and former smokers $\quad(\mathrm{OR}=4 \cdot 75 ; \quad 95 \%$ CI $1 \cdot 40, \quad 16 \cdot 15$; $P=0 \cdot 013)$. The odds were non-statistically significantly elevated for current smokers (OR $=1 \cdot 95 ; 95 \%$ CI $0 \cdot 73$, $5 \cdot 22 ; P=0 \cdot 183)$ and reduced for former smokers $(\mathrm{OR}=$ $0 \cdot 41 ; 95 \%$ CI $0 \cdot 15,1 \cdot 12 ; P=0 \cdot 083)$. Two other variables

Table 2 Univariate logistic regression analysis for predictors of being a non-completer of group non-dieting interventions for overweight women, Dunedin, New Zealand, 2002-3

\begin{tabular}{|c|c|c|c|}
\hline Variable & OR & $95 \% \mathrm{Cl}$ & $P$ value \\
\hline \multicolumn{4}{|l|}{ Non-modifiable } \\
\hline \multicolumn{4}{|l|}{ Education } \\
\hline Did not complete high school $v$. completed at least high school & $2 \cdot 59$ & $1 \cdot 02,6 \cdot 60$ & $0.046^{*}$ \\
\hline \multicolumn{4}{|l|}{ Relationship status } \\
\hline With partner $v$. without partner & $1 \cdot 07$ & $0 \cdot 47,2 \cdot 48$ & 0.866 \\
\hline With children $v$. without children & 1.46 & $0.70,3.05$ & 0.308 \\
\hline Occupation & & & 0.820 \\
\hline Employed full-time $v$. employed part-time & 1.08 & $0.46,2 \cdot 54$ & \\
\hline Employed part-time $v$. not employed & $0 \cdot 80$ & $0.32,1.99$ & \\
\hline \multicolumn{4}{|l|}{ Modifiable (controlling for education) } \\
\hline $\mathrm{BMI}\left(\mathrm{kg} / \mathrm{m}^{2}\right)$ & 1.03 & $0 \cdot 97,1 \cdot 11$ & 0.319 \\
\hline Weight $(\mathrm{kg})$ & $1 \cdot 01$ & $0.99,1.04$ & 0.400 \\
\hline Smoking & & & 0.043 \\
\hline Current smoker $v$. never smoker & $1 \cdot 95$ & $0 \cdot 73,5 \cdot 22$ & \\
\hline Former smoker $v$. never smoker & $0 \cdot 41$ & $0 \cdot 15,1 \cdot 12$ & \\
\hline \multicolumn{4}{|l|}{ Blood pressure $(\mathrm{mmHg})$} \\
\hline Systolic & 0.98 & $0.95,1.00$ & 0.076 \\
\hline Diastolic & 0.98 & $0.95,1.02$ & 0.348 \\
\hline \multicolumn{4}{|l|}{ Eating self-efficacy scoret } \\
\hline Negative affect & $1 \cdot 00$ & $0.99,1.02$ & 0.676 \\
\hline Socially acceptable circumstances & 0.98 & $0.95,1.02$ & 0.317 \\
\hline \multicolumn{4}{|l|}{ HPLP-II } \\
\hline Nutrition & $0 \cdot 40$ & $0 \cdot 19,0 \cdot 85$ & $0.017^{*}$ \\
\hline Physical activity & 0.57 & $0 \cdot 27,1 \cdot 23$ & $0 \cdot 153$ \\
\hline Stress management & 1.00 & $0 \cdot 42,2 \cdot 37$ & 0.993 \\
\hline \multicolumn{4}{|l|}{ SCL-90-R $\$$} \\
\hline GSI & 0.93 & $0 \cdot 37,2 \cdot 36$ & 0.879 \\
\hline Depression & 1.02 & $0.57,1.84$ & 0.945 \\
\hline Anxiety & $1 \cdot 02$ & $0 \cdot 44,2 \cdot 39$ & 0.955 \\
\hline Hostility & 1.01 & $0.53,1.92$ & 0.987 \\
\hline Interpersonal sensitivity & 0.64 & $0 \cdot 32,1 \cdot 29$ & 0.213 \\
\hline Obsessive compulsive & $1 \cdot 00$ & $0.51,1.93$ & 0.990 \\
\hline Paranoid ideation & $0 \cdot 88$ & $0.39,1.97$ & 0.752 \\
\hline Phobic & $0 \cdot 36$ & $0.07,1 \cdot 85$ & 0.223 \\
\hline Psychotic & 0.54 & $0 \cdot 16,1 \cdot 80$ & 0.314 \\
\hline Somatization & $1 \cdot 39$ & $0.65,2.95$ & 0.398 \\
\hline
\end{tabular}

HPLP-II, Health-Promoting Lifestyle Profile II; SCL-90-R, Revised Symptom Checklist-90; GSI, Global Severity Index.

${ }^{\star} P<0.05$.

tEating self-efficacy factors were rated on a 7-point Likert scale from 1 (no difficulty controlling overeating) to 7 (most difficulty controlling). Lower scores indicate higher self-efficacy.

‡Dimensions of the HPLP-II were scored using a Likert scale from 1 (never) to 4 (routinely). Higher scores indicate healthier behaviours.

\$The SCL-90-R was scored on a 5-point scale from 0 (not at all) to 4 (extremely). Lower scores indicate lower levels of psychological stress. 
also had $P<0 \cdot 10$, showing potential for differentiating non-completers from completers: systolic blood pressure $(\mathrm{OR}=0.98 ; 95 \% \mathrm{CI} 0.95,1 \cdot 00 ; P=0 \cdot 076)$ and (HPLP-II) nutrition $(\mathrm{OR}=0 \cdot 40 ; 95 \%$ CI $0 \cdot 19, \quad 0 \cdot 85 ; \quad P=0 \cdot 017$; Table 2). These univariate results indicate that current smoking was associated with higher odds of being a noncompleter, whereas higher nutrition values and higher blood pressure were associated with lower odds of being a non-completer.

Based on the results from these preliminary models, a final multiple logistic regression model was created using education, smoking status, systolic blood pressure and HPLP-II nutrition score to assess their independent effects on non-completion status (Table 3). After controlling for

Table 3 Multiple logistic regression analysis for independent predictors of being a non-completer of group non-dieting interventions for overweight women, Dunedin, New Zealand, 2002-3

\begin{tabular}{llll}
\hline Independent variable & OR & $95 \% \mathrm{Cl}$ & $P$ value \\
\hline Smoking status & & & 0.076 \\
$\quad$ Current smoker $v$. never smoker & 1.93 & $0.70,5.36$ & \\
$\quad$ Former smoker v. never smoker & 0.45 & $0.16,1.28$ & \\
Systolic blood pressure & 0.98 & $0.95,1.00$ & 0.070 \\
Nutrition (HPLP-II)† & 0.46 & $0.21,1.00$ & $0.0497^{*}$ \\
Education & 2.31 & $0.83,6.39$ & 0.108 \\
\hline
\end{tabular}

HPLP-II, Health-Promoting Lifestyle Profile II.

${ }^{*} P<0.05$.

tSee Table 2 for details of measure. other variables in the model, only nutrition behaviours significantly differentiated non-completers from completers. Specifically, women with higher nutrition scores at baseline were less likely to be non-completers $(\mathrm{OR}=$ $0 \cdot 46 ; 95 \%$ CI $0 \cdot 21,1 \cdot 00 ; P=0 \cdot 0497)$. There was also a tendency for higher values of systolic blood pressure to be associated with lower odds of being a non-completer (OR $=0.98 ; 95 \%$ CI 0.95, 1.00; $P=0 \cdot 070)$. Additionally, there was a tendency for a difference between smoking categories (overall $P=0 \cdot 076$ ). While this was not statistically significant, we note that current smokers had higher odds of being non-completers compared with never-smokers (OR $=1 \cdot 93$; $95 \%$ CI 0•70, 5·36). However, former smokers were less likely to be non-completers than never smokers $(\mathrm{OR}=0 \cdot 45 ; 95 \%$ CI $0 \cdot 16,1 \cdot 28)$.

\section{Changes in outcome measures over time in completers and non-completers}

Baseline values and change scores at 10 weeks and 12 months for outcome variables are shown in Table 4. At the end of the 10-week programme, completers showed significantly greater improvements in stress management and interpersonal sensitivity than non-completers. At the 12-month follow-up, completers had lost on average $0.5 \mathrm{~kg}$ and experienced decreases in blood pressure of $6 \cdot 3 \mathrm{mmHg}$ (systolic) and $4 \cdot 1 \mathrm{mmHg}$ (diastolic). Over the same time period, non-completers had gained $2 \cdot 6 \mathrm{~kg}$ and

Table 4 Baseline means, and 10-week and 12-month changes in outcome variables for completers $(n 69)$ and non-completers $(n 50)$ of group non-dieting interventions for overweight women, Dunedin, New Zealand, 2002-3

\begin{tabular}{|c|c|c|c|c|c|c|c|c|c|c|c|c|}
\hline \multirow[b]{3}{*}{ Variable } & \multicolumn{4}{|c|}{ Baseline } & \multicolumn{4}{|c|}{ 10-week change } & \multicolumn{4}{|c|}{ 12-month change } \\
\hline & \multicolumn{2}{|c|}{ Completers } & \multicolumn{2}{|c|}{ Non-completers } & \multicolumn{2}{|c|}{ Completers } & \multicolumn{2}{|c|}{ Non-completers } & \multicolumn{2}{|c|}{ Completers } & \multicolumn{2}{|c|}{ Non-completers } \\
\hline & Mean & SD & Mean & SD & Mean & SD & Mean & SD & Mean & SD & Mean & SD \\
\hline Weight $(\mathrm{kg})$ & $93 \cdot 6$ & $15 \cdot 4$ & $95 \cdot 7$ & $15 \cdot 1$ & 0.0 & $2 \cdot 9$ & 0.0 & $2 \cdot 9$ & $-0 \cdot 5^{\star}$ & $5 \cdot 2$ & $2 \cdot 6$ & $3 \cdot 6$ \\
\hline $\operatorname{BMI}\left(\mathrm{kg} / \mathrm{m}^{2}\right)$ & $34 \cdot 9$ & $5 \cdot 4$ & $36 \cdot 0$ & $6 \cdot 0$ & $0 \cdot 1$ & $1 \cdot 1$ & -0.9 & $5 \cdot 4$ & $-0 \cdot 2^{*}$ & 1.9 & $1 \cdot 0$ & $1 \cdot 3$ \\
\hline \multicolumn{13}{|l|}{ Blood pressure $(\mathrm{mmHg})$} \\
\hline Systolic & $137 \cdot 1$ & $16 \cdot 7$ & $131 \cdot 7$ & $15 \cdot 1$ & $-1 \cdot 1$ & $13 \cdot 3$ & $0 \cdot 3$ & $12 \cdot 4$ & $-6 \cdot 3^{\star}$ & $13 \cdot 8$ & $6 \cdot 2$ & $14 \cdot 1$ \\
\hline Diastolic & $84 \cdot 9$ & $10 \cdot 2$ & $83 \cdot 2$ & $10 \cdot 8$ & $-1 \cdot 4$ & $9 \cdot 4$ & $-4 \cdot 3$ & $8 \cdot 6$ & $-4 \cdot 1^{*}$ & $10 \cdot 1$ & $2 \cdot 0$ & $10 \cdot 2$ \\
\hline \multicolumn{13}{|l|}{ Eating self-efficacy scoret } \\
\hline Negative affect & $59 \cdot 8$ & $23 \cdot 2$ & $62 \cdot 3$ & $23 \cdot 9$ & $-2 \cdot 7$ & $23 \cdot 2$ & $-9 \cdot 4$ & $30 \cdot 8$ & $-8 \cdot 6$ & $25 \cdot 4$ & $-9 \cdot 2$ & $29 \cdot 9$ \\
\hline Socially acceptable circumstances & $42 \cdot 7$ & $10 \cdot 1$ & $40 \cdot 9$ & $10 \cdot 4$ & $-2 \cdot 4$ & $10 \cdot 9$ & $-3 \cdot 0$ & $16 \cdot 8$ & $-5 \cdot 6$ & $10 \cdot 2$ & $1 \cdot 2$ & $14 \cdot 9$ \\
\hline \multicolumn{13}{|l|}{ HPLP-IIt } \\
\hline Nutrition & $2 \cdot 8$ & $0 \cdot 6$ & $2 \cdot 5$ & 0.5 & 0.3 & 0.5 & $0 \cdot 3$ & 0.5 & 0.5 & 0.5 & 0.3 & $0 \cdot 4$ \\
\hline Physical activity & $1 \cdot 8$ & 0.5 & $1 \cdot 7$ & 0.5 & 0.4 & 0.5 & 0.2 & $0 \cdot 4$ & $0 \cdot 6$ & 0.6 & 0.5 & 0.4 \\
\hline Stress management & $2 \cdot 1$ & $0 \cdot 4$ & $2 \cdot 1$ & 0.4 & $0 \cdot 4^{*}$ & $0 \cdot 6$ & 0.2 & $0 \cdot 3$ & $0 \cdot 5^{\star}$ & 0.5 & 0.2 & $0 \cdot 4$ \\
\hline \multicolumn{13}{|l|}{ SCL-90-Rt } \\
\hline GSI & 0.5 & $0 \cdot 4$ & 0.5 & 0.4 & $-0 \cdot 1$ & $0 \cdot 3$ & $-0 \cdot 1$ & $0 \cdot 2$ & -0.2 & $0 \cdot 3$ & $-0 \cdot 2$ & $0 \cdot 2$ \\
\hline Depression & 0.8 & $0 \cdot 6$ & $0 \cdot 8$ & $0 \cdot 7$ & $-0 \cdot 2$ & 0.5 & $-0 \cdot 1$ & $0 \cdot 4$ & $-0 \cdot 3$ & 0.5 & $-0 \cdot 3$ & $0 \cdot 4$ \\
\hline Anxiety & 0.4 & 0.5 & 0.4 & 0.4 & $-0 \cdot 1$ & $0 \cdot 4$ & $-0 \cdot 1$ & 0.3 & $-0 \cdot 2$ & $0 \cdot 4$ & -0.2 & $0 \cdot 3$ \\
\hline Hostility & 0.4 & 0.5 & 0.5 & 0.6 & $-0 \cdot 2$ & 0.5 & $-0 \cdot 2$ & $0 \cdot 3$ & -0.3 & 0.5 & $-0 \cdot 2$ & $0 \cdot 4$ \\
\hline Interpersonal sensitivity & 0.5 & $0 \cdot 6$ & $0 \cdot 6$ & 0.5 & $-0.3^{*}$ & 0.5 & $-0 \cdot 1$ & $0 \cdot 4$ & -0.4 & 0.5 & -0.2 & $0 \cdot 3$ \\
\hline Obsessive compulsive & 0.7 & $0 \cdot 6$ & $0 \cdot 7$ & -0.5 & $-0 \cdot 1$ & 0.5 & $-0 \cdot 1$ & $0 \cdot 4$ & -0.2 & 0.4 & $-0 \cdot 2$ & $0 \cdot 3$ \\
\hline Paranoid ideation & 0.4 & 0.5 & $0 \cdot 4$ & 0.4 & $-1 \cdot 0$ & $0 \cdot 4$ & -0.9 & $0 \cdot 3$ & $-0 \cdot 2$ & $0 \cdot 4$ & -0.2 & $0 \cdot 3$ \\
\hline Phobic & 0.1 & $0 \cdot 3$ & 0.09 & 0.2 & -0.8 & 0.3 & -0.1 & $0 \cdot 1$ & -0.1 & 0.2 & 0.0 & $0 \cdot 1$ \\
\hline Psychotic & 0.2 & $0 \cdot 4$ & $0 \cdot 2$ & 0.3 & $-0 \cdot 1$ & $0 \cdot 3$ & $-0 \cdot 1$ & $0 \cdot 2$ & $-0 \cdot 1^{*}$ & 0.3 & 0.0 & $0 \cdot 1$ \\
\hline Somatization & 0.5 & 0.5 & $0 \cdot 7$ & 0.5 & -0.1 & $0 \cdot 4$ & -0.1 & 0.4 & $0 \cdot 1$ & $0 \cdot 4$ & 0.0 & 0.4 \\
\hline
\end{tabular}

HPLP-II, Health-Promoting Lifestyle Profile II; SCL-90-R, Revised Symptom Checklist-90; GSI, Global Severity Index. ${ }^{*} P<0.05$ for between-group difference ( $t$ test) at 10 weeks or 12 months.

tSee Table 2 for details of measures. 
experienced increases in blood pressure of $6.2 \mathrm{mmHg}$ (systolic) and $2 \cdot 0 \mathrm{mmHg}$ (diastolic). Furthermore, completers experienced greater improvements in stress management behaviours (HPLP-II) and a decrease in the psychotic subscale of the SCL-90-R (Table 4). All of these between-group differences were statistically significant $(P<0 \cdot 05)$.

\section{Discussion}

The current study indicates that, among overweight and obese women, a number of factors predict noncompletion at non-dieting group interventions. Nutrition behaviours significantly differentiated non-completers from completers after controlling for other factors in the model; there was also a tendency for systolic blood pressure, smoking status and education to differentiate the two groups. Specifically, women who had poorer nutrition behaviours at baseline and had not completed high school or pursued further education were less likely to complete non-dieting group interventions. Surprisingly, there was a tendency for those with lower baseline systolic blood pressure to be non-completers. There was also a tendency for smoking to have an overall effect on non-completion, with current smokers having higher odds and former smokers having lower odds of not completing the interventions compared with never smokers.

It is possible that education level is a marker of socioeconomic status in the present study. Other researchers have reported that socio-economic status is predictive of attendance at programmes focused on elicitation of the relaxation response ${ }^{(22)}$. It is possible that lower socio-economic status may negatively influence attendance owing to factors such as lack of childcare, employment situation (e.g. inflexible work hours) or reliance on public transport.

Findings from the Harvard Medical Symptom Reduction programme have suggested that baseline depression and other psychological distress measures are lower among completers than among non-completers ${ }^{(22,24,25)}$. Thus we were surprised to observe that pre-treatment SCL-90-R depression and anxiety scores did not significantly differentiate completers from non-completers.

Importantly, our results demonstrate that regular attendance translated into improved long-term outcomes. At the 12-month follow-up, compared with non-completers, completers had significantly greater improvements in body weight, systolic and diastolic blood pressure, and stress management behaviours. These findings suggest that attendance is of great importance to the success of group non-dieting programmes.

Although most trials of non-dieting interventions to date have reported weight maintenance (i.e. prevention of further weight gain), findings from the current study suggest that weight outcomes may differ significantly depending on group programme attendance. It is possible that women who are more highly motivated or better suited to the non-dieting approach may experience a small but gradual weight loss over time. Further research is needed to explore this hypothesis.

In light of the improved outcomes associated with completion of non-dieting group programmes, it would be useful to develop and evaluate strategies to improve attendance at such programmes. Preparatory interventions such as role induction or motivational interviewing have been shown to improve attendance at other group programmes, including a group-based psychological treatment $^{(32)}$ and a behavioural weight-loss programme ${ }^{(33)}$. Thus, it is possible that a preparatory phase may also improve attendance for non-dieting group programmes. The length of successful preparatory interventions has varied from an 11-minute role induction videotape to four 60-minute sessions of experiential pre-training ${ }^{(32)}$. In the future, a short preparatory phase could enable programme facilitators to use motivational interviewing techniques to enhance participant readiness to adopt a non-dieting approach, including a shift in focus away from weight-loss goals. This approach in turn may improve attendance.

The present study has two limitations of note. First, for statistical reasons we employed a stringent cut-off point for regular attendance. Participants were required to have attended at least eight out of ten sessions to be categorised as a completer. If we had used a cut-off of seven sessions to denote completion, the logistic regression model would have been severely compromised. Second, we combined data from two non-dieting group interventions; however, most intervention-by-predictor interactions were non-significant.

The results of the study indicate that nutrition behaviours, systolic blood pressure, smoking status and education may predict non-completion in non-dieting group interventions. These findings may allow researchers to identify those at risk of non-completion and to develop strategies to improve attendance, and thus treatment outcomes. Such strategies could include, for example, group-based preparatory or orientation sessions prior to the start of the programme, email or telephone reminders about session dates and times, provision of childcare, subsidized transport costs or catch-up sessions. Investigation of the effects on both attendance and outcomes of adding a preparatory phase to non-dieting group programmes would be valuable. It is particularly important that future studies of non-dieting group interventions examine the effects of attendance on treatment outcomes. Trials of non-dieting treatments have concluded that this approach prevents weight gain ${ }^{(5,7,11,15,16,19,20)}$; however, our study suggests that weight and blood pressure outcomes may vary significantly according to attendance, with a gradual weight loss occurring for those who complete group interventions. 


\section{Acknowledgements}

This work was supported by Bristol Myers Squibb, a Laurenson Award and the Department of Human Nutrition, University of Otago. The authors declare no conflicts of interest. A.J.B. drafted and revised the paper, A.G. conducted the statistical analyses, and C.C.H., L.K. and A.G. commented upon and revised drafts. All authors give their approval to the final version submitted for publication. Grateful thanks to practitioners Sue O'Brien and Janine Joyce for their work on the interventions, and to Jennifer Jabs for research assistance.

\section{References}

1. Mann T, Tomiyama AJ, Westling E et al. (2007) Medicare's search for effective obesity treatments: diets are not the answer. Am Psychol 62, 220-233.

2. Miller WC (1999) How effective are traditional dietary and exercise interventions for weight loss? Med Sci Sports Exerc 31, 1129-1134.

3. Miller WC \& Jacob AV (2001) The health at any size paradigm for obesity treatment: the scientific evidence. Obes Rev 2, 37-45.

4. McFarlane T, Polivy J \& McCabe RE (1999) Help, not harm: psychological foundation for a nondieting approach toward health. J Soc Issues 55, 261-276.

5. Bacon L, Stern JS, Van Loan MD et al. (2005) Size acceptance and intuitive eating improve health for obese, female chronic dieters. J Am Diet Assoc 105, 929-936.

6. Kausman R (1998) If Not Dieting, Then What? Sydney: Allen \& Unwin.

7. Bacon L, Keim NL, Van Loan MD et al. (2002) Evaluating a 'non-diet' wellness intervention for improvement of metabolic fitness, psychological well-being and eating and activity behaviors. Int $J$ Obes Relat Metab Disord 26, 854-865.

8. Higgins LC \& Gray W (1999) What do anti-dieting programmes achieve? A review of research. Aust J Nutr Diet 56, 128-136.

9. Foreyt JP \& Goodrick GK (1993) Weight management without dieting. Nutr Today March-April, 4-9.

10. Provencher V, Begin C, Tremblay A et al. (2007) Short-term effects of a 'health-at-every-size' approach on eating behaviors and appetite ratings. Obesity (Silver Spring) 15, 957-966.

11. Goodrick GK, Poston WS, KIimball KT et al. (1998) Nondieting versus dieting treatment of overweight binge-eating women. J Consult Clin Psychol 66, 363-368.

12. Rapoport L, Clark M \& Wardle J (2000) Evaluation of a modified cognitive-behavioural programme for weight management. Int J Obes Relat Metab Disord 24, 1726-1737.

13. Tanco S, Linden W \& Earle T (1998) Well-being and morbid obesity in women: a controlled therapy evaluation. Int J Eat Disord 23, 325-339.

14. Nauta H, Hospers H, Kok G et al. (2000) A comparison between a cognitive and a behavioural treatment for obese binge eaters and obese non-binge eaters. Behav Ther 31, $441-461$.
15. Nauta H, Hospers H \& Jansen A (2001) One-year follow-up effects of two obesity treatments on psychological wellbeing and weight. BrJ Health Psychol 6, 271-284.

16. Ciliska D (1990) Beyond Dieting. Psychoeducational Interventions for Chronically Obese Women: A Non-dieting Approach. New York: Brunner/Mazel.

17. Higgins LC \& Gray W (1998) Changing the body image concern and eating behaviour of chronic dieters: the effects of a psychoeducational intervention. Psychol Health 13, 1045-1060.

18. Munsch S, Biedert E \& Keller U (2003) Evaluation of a lifestyle change programme for the treatment of obesity in general practice. Swiss Med Wkly 133, 148-154.

19. Rosen JC, Orosan P \& Reiter J (1995) Cognitive behaviour therapy for negative body image in obese women. Behav Ther 26, 25-42.

20. Katzer L, Bradshaw AJ, Horwath CC et al. (2008) Evaluation of a 'non-dieting' stress reduction program for overweight women: a randomized trial. Am J Health Promot 22, 264-274.

21. Carroll S, Borkoles E \& Polman R (2007) Short-term effects of a non-dieting lifestyle intervention program on weight management, fitness, metabolic risk, and psychological well-being in obese premenopausal females with the metabolic syndrome. Appl Physiol Nutr Metab 32, 125-142.

22. Nakao M, Fricchione GL, Myers P et al. (2001) Depression and education as predicting factors for completion of a behavioral medicine intervention in a Mind/Body medicine clinic. Behav Med 26, 177-184.

23. Clark M, Niaura R, King $\mathrm{T}$ et al. (1996) Depression, smoking, activity level, and health status: pretreatment predictors of attrition in obesity treatment. Addict Behav 21, 509-513.

24. Nakao M, Fricchione GL, Myers P et al. (2001) Anxiety is a good indicator for somatic symptom reduction through behavioural medicine intervention in a mind-body clinic. Psychother Psychosom 70, 50-57.

25. Nakao M, Myers P, Fricchione GL et al. (2001) Somatization and symptom reduction through a behavioral medicine intervention in a Mind/Body clinic. Behav Med 26, 169-176.

26. Bandura A (1986) Social Foundations of Thought and Action: A Social Cognitive Theory. Englewood Cliffs, NJ: Prentice Hall.

27. Noble Walker S, Sechrist KR \& Pender NJ (1987) The health-promoting lifestyle profile: development and psychometric characteristics. Nurs Res 36, 76-81.

28. Glynn SM \& Ruderman AJ (1986) The development and validation of an eating self-efficacy scale. Cognit Ther Res 10, 403-420.

29. Derogatis LR (1994) SCL-90-R Administration, Scoring, and Procedures, 3rd ed. Minneapolis, MN: National Computer Systems, Inc.

30. Williams KA, Kolar MM, Reger BE et al. (2001) Evaluation of a wellness-based mindfulness stress reduction intervention: a controlled trial. Am J Health Promot 15, 422-432.

31. Littell RC, Milliken GA, Stroup WW et al. (1996) SAS System for Mixed Models. Cary, NC: SAS Institute.

32. Walitzer K, Dermen K \& Connors G (1999) Strategies for preparing clients for treatment: a review. Behav Modif 23, 129-151.

33. Goldberg JH \& Kiernan M (2005) Innovative techniques to address retention in a behavioral weight-loss trial. Health Educ Res 20, 439-447. 